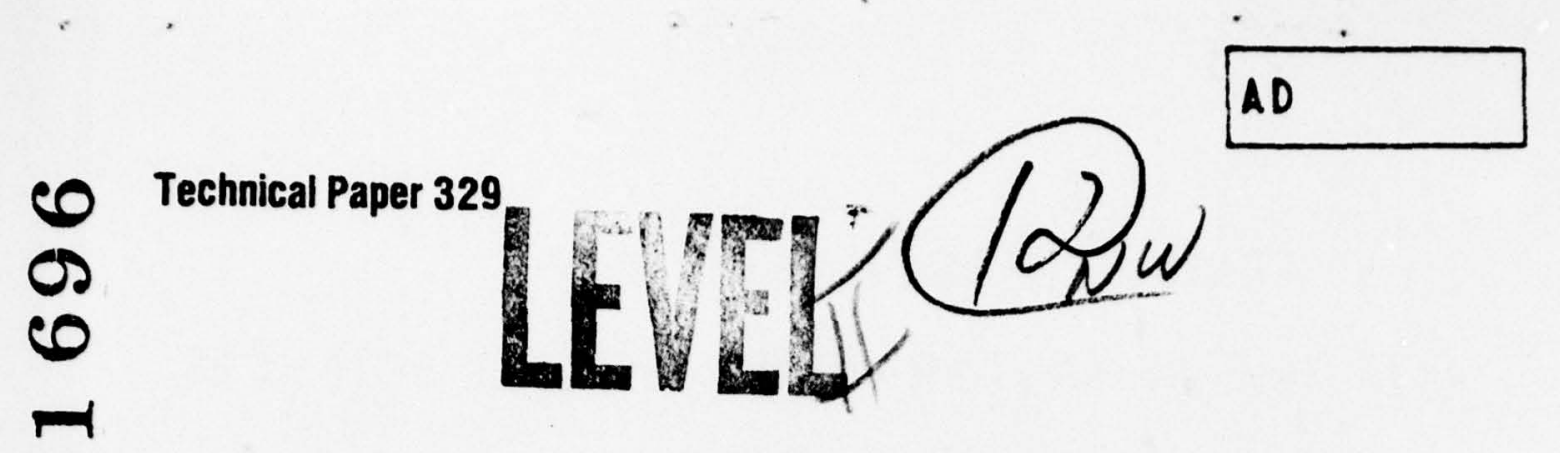

\title{
AN EVALUATION OF TWO SYSTEMS FOR REDUCING DISCIPLINE FAILURE IN BCT
}

D. Bruce Bell

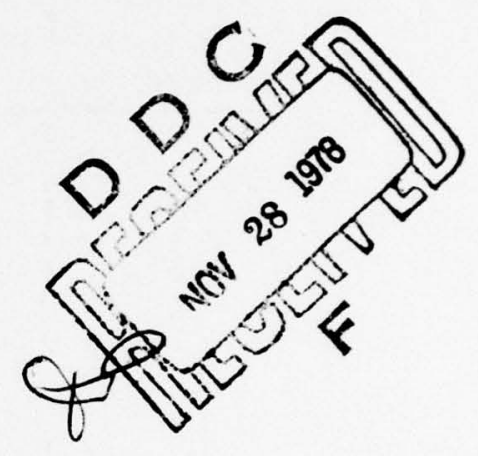

PERSONNEL ACCESSION AND UTILIZATION TECHNICAL AREA

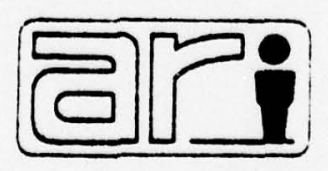

U. S. Army

Research Institute for the Behavioral and Social Sciences

September 1978

Approved for public release. distribution unlimited.

78112 


\title{
U. S. ARMY RESEARCH INSTITUTE \\ FOR THE BEHAVIORAL AND SOCIAL SCIENCES
}

\author{
A Field Operating Agency under the Jurisdiction of the \\ Deputy Chief of Staff for Personnel
}

JOSEPH ZEIDNER

WILLIAM L. HAUSER

Technical Director

Colonel, US Army

Commander

NOTICES

DISTRIBUTION Primary distribution of this report has been made by ARI. Please eddress correspondence concerning distribution of reports to: U. S. Army Research Institute for the Behavioral and Social Sciences, ATTN PERI.P, 5001 Eisenhower Avenue, Alexandria, Virginia 22333.

EINAL DISPOSITUON This report mav be destroyed when it is no longer needed. Please do not return it to the U. S. Army Research Institute for the Behevioral and Social Sciences.

NeTE The findings in this report are not to be construed es on official Depertment of the Army position, uniess so designated by other euthorized documents. 
SECURITY CLASSIFICATION OF THIS PAGE (When Date Entered)

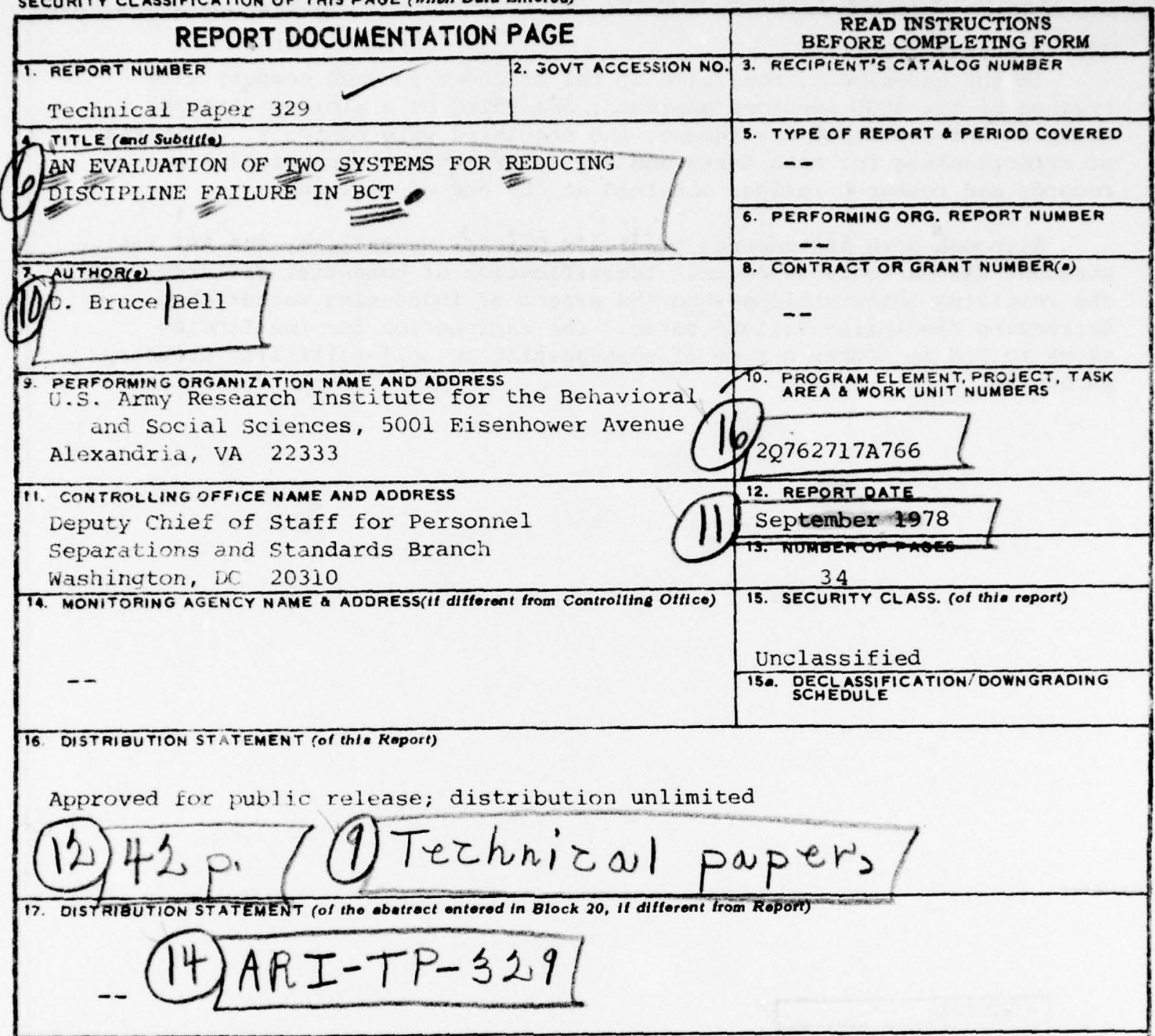

18. SUPPLEMENTARY NOTES

19. $K E Y$ WORDS (Continue on reverse side if necessary and identify by block number)

Delinquency

Discipline failure

AWOL

Counseling

Basic Combat Training

20 ABSTAAC (Continue on reverse side If necessary and tenthly by block number)

Che research had two purposes: io determine the predictive validity of two instruments designed to predict discipline failure in Basic combat Training; and to evaluate the effectiveness of company level interventions using information obtained from them.

408010

DD, FORM 1473 EDITION OF I NOV 65 IS OBSOLETE

Unclassified

SECURITY CLASSIFICATION OF THIS PAGE (When Date Entered) 
20. Abstract (cont)

In the experiment, one-third of the trainees in each company were treated by the AWOL syndrome approach; one-third by a similar strategy using an ARI-developed instrument; and one-third were controls. Criteria of effectiveness for both tests and the interventions were discipline records and research ratings obtained at the end of training.

Although both instruments predicted discipline failure, the ARI instrument was markedly superior. Identification of potential failures--and the resulting interventions--had the effect of increasing rather than decreasing discipline failure rates. The explanation for the finding seems to lie in either a type of scapegoating or self-fulfilling prophecy mechanism.

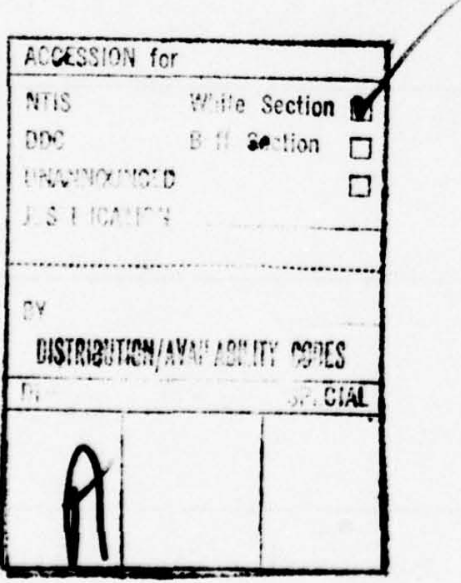




\title{
AN EVALUATION OF TWO SYSTEMS FOR REDUCING DISCIPLINE FAILURE IN BCT
}

\author{
D. Bruce Bell
}

PERSONNEL ACCESSION AND UTILIZATION TECHNICAL AREA

Submitted as complete and technically accurate, by:

Ralph R. Canter

Technical Area Chlef
Approved By:

E. Ralph Dusek, Director INDIVIDUAL TRAINING AND PERFORMANCE RESEARCH LABORATORY

Joseph Zeidner

TECHNICAL DIRECTOR

U.S. ARMY RESEARCH INSTITUTE FOR THE BEHAVIORAL AND SOCIAL SCIENCES 5001 Eisenhower Avenue, Alexandria, Virginia 22333

Office, Deputy Chief of Staff for Personnel

Department of the Army

\section{September 1978}


ARI Research Reports and Technical Papers are intended for sponsors of R\&D tasks and other research and military agencies. Any findings ready for implementation at the time of publication are presented in the latter part of the Brief. Upon completion of a major phase of the task, formal recommendations for official action normally are conveyed to appropriate military agencies by briefing or Disposition Form. 
In the fall of 1971, the Separations and Standards Branch of the Office of the Deputy Chief of Staff for Personnel, Department of the Army (DCSPER, DA), requested an evaluation of the effectiveness of a new system for reducing discipline problems in Basic Combat Training. Evaluation by the Army Research Institute (ARI) included not only a test of the system then in use but also an alternative system based on work in military delinquency going back to the end of World War II.

Since this evaluation was completed and reported to the DCSPER in 1973, ARI has continued to conduct research into the causes of and ways to reduce military delinquency. An appendix lists major ARI publications in this field. Dr. S. F. Bolin, Mr. D. M. Kristiansen, and Mr. T. J. Houston also worked on this project during 1972-73. This evaluation was accomplished under Army Project 2Q763731A769 (FY 74); the continuing research is done under Project 2Q762717A766 (FY 78), Enlisted Accession and Utilization.

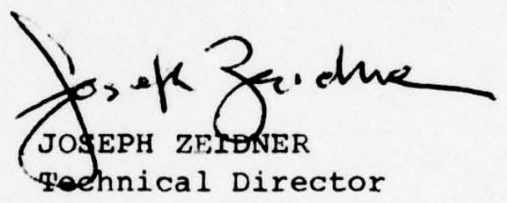


AN EVALUATION OF TWO SYSTEMS FOR REDUCING DISCIPLINE FAILURE IN BCT

BRTEF

Requirement:

To (a) determine the usefulness of two paper-and-pencil instruments in predicting discipline failure among individuals undergoing basic combat training (BCT), and (b) evaluate the effectiveness of company-level leaders in reducing discipline failure among those identified by the tests.

Proceaure:

In the experiment, one--third of the trainees were treated by the AWOL synarome approach and one-third by a similar strategy using an ARIdeveloped instrument; the remainder were controls. Each group had over 1,600 cases. About 108 of each group were selected for company commander interview. In the experimental groups, selection was based on test scores; in the control group, selection was random. Criteria of both test and intervention effectiveness were based on official discipline data and research ratings obtained at the end of training.

Findings :

Although both instruments predicted discipline failure at a statistical level, the ARI instrument was markedly superior (the tetrachoric correlations were .12 and .32 , respectively). However, neither instrument possessed sufficient predictive validities to be used for operational purposes.

Identification of potential discipline failures among trainees had the effect of increasing the chances that those identified would experience failure. The reason for the increased rates seems to lie in some type of scapegoating or self-fulfilling prophecy mechanisms.

Utilization of Findings:

Results of this experiment formed the basis for the decision to eliminate ail programs based on the AWOL syndrome approach. Prior to the experiment, that approach had been tried widely and was being considered for Army-wide implementation. Valid questions from the ARI instrument were incorporated into the current ARI instrument for predicting early attrition.

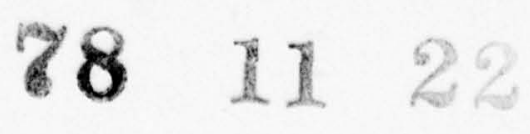


AN EVALUATION OF TWO SYSTEMS FOR REDUCING DISCIPLINE FAILURE IN BCT

INTRODUCTION . . . . . . . . . . . . . . . . . . . . 1

METHOD . . . . . . . . . . . . . . . . . . . . . 2

Assignment of Individuals to Treatment Conditions . . . . . . 2

Conduct of Interviews and Follow-Up Actions . . . . . . . . . 3

Gathering of Criterion Data . . . . . . . . . . . . . 3

Further Processing of the Control Group . . . . . . . . . . 5

Analysis of the Data . . . . . . . . . . . . . . . 5

RESULTS . . . . . . . . . . . . . . . . . . . 7

How Predictive of Discipline Failure are the Two

Instruments? .. . . . . . . . . . . . . . . 7

How Effective is the Use of Instruments in the

Referral Process? . . . . . . . . . . . . . . 9

How Effective is Referral for Interview Alone? . . . . . . . 11

DISCUSSION . . . . . . . . . . . . . . . . . . . 14

Relationship of the TJTA and BOQ-72 to

Discipline Failure . . . . . . . . . . . . . . . 14

The Role of Identification and Referral Systems

in Reducing Discipline Failure . . . . . . . . . . . 17

Conclusions and Suggestions for Further Research . . . . . . 19

REFERENCES . . . . . . . . . . . . . . . . . . . . . 21

DISTRIBUTION . . . . . . . . . . . . . . . . . . • 33

APPENDIX A: Recent Army Research Institute Publications

on Military Delinquency............ 23

B: Prediction of AWOL Using the TJTA . . . . . . . 25

LIST OF TABLES

Table 1. Analyses of noninterview-control group for prediction effects................. 8

2. Effect of TJTA referral on discipline failure rates ... . . . . . . . . . . . . 10 
LIST OF TABLES (continued)

Table 3. Relationship between risk, outcome, and referral

for the TJTA . . . . . . . . . . . . . . 11

4. Effect of $\mathrm{BOQ}$ referral on discipline failure rates . . 12

5. Relationship between risk, outcome, and referral

for the $B O Q$. . . . . . . . . . . . 12

6. Effect of referral for interview in the absence

of instruments................ 13

B-1. Predictive validity of the TJTA for prisoners • • • 26

B-2. TJTA prediction of AWOL for the control-

noninterview group ... . . . . . . . . . 27

B-3. TJTA prediction of AWOL in the TJTA sample . . . . . 27

B-4. TJTA prediction of AWOL in BCT at Fort Polk . . . . 28

B-5. TJTA prediction of AWOL in BCT at Fort

Leonard Wood . . . . . . . . . . . . . 30

\section{LIST OF FIGURES}

Figure 1. Testing, scoring, and referral procedures

for BCT companies .. . . . . . . . . . . . 4

2. Results of processing the control-

noninterview group .. . . . . . . . . . 6 


\section{AN EVALUATION OF TWO SYSTEMS FOR REDUCING DISCIPLINE \\ FAILURE IN BCT}

\section{INTRODUCTION}

The Army is always interested in new techniques for reducing disciplinary problems, particularly among troops in basic combat training (BCT); in BCT, men form patterns of behavior that may remain throughout their Almy careers. Therefore, a report by an Army chaplain suggesting a way to reduce absence without leave (AWOL) in BCT aroused considerable interest (Berbiglia, 1971). This report evaluates Berbiglia's system in comparison with a measure of discipline developed by the Army Research Institute (ARI), as part of continuing ARI research on military delinquency (see Appendix A).

Berbiglia's system had two parts: identification of "Awol-prone" soldiers and provision of services to them to prevent AWOL or other discipline problems. Such identification was based on a 180-item temperament profile test--the Taylor Johnson Temperament Analysis (TJTA) (Taylor, Morrison, Morrison, \& Romoser, 1968). Earlier research by Berbiglia showed that the TJTA could differentiate between men who were in the stockade for AWOL offenses and other prisoners. AWOL soldiers described themseives as nervous, depressed, quiet, inhibited, hostile, or impulsive. Extreme scores on four or more of these six traits constituted the AWOL symarome.

Men identified as exhibiting the AWOL syndrome were referred to their company commanders for interviews and to Berbiglia for counseling or other appropriate follow-up services. Although Berbiglia reported highly promising results for this approach, the existence of an AWOL syndrome was challenged (Fraas \& Fox, 1972) (see also Appendix B).

The purpose of the experiment reported here was to evaluate the effectiveness of identification and referral as a means of reducing discipline failure in $\mathrm{BCT}$. A second identification instrument was included to avoid conclusions based upon any TJTA idiosyncrasy--the Background and Opinion Questionnaire-72 (BOQ-72) (Be11, Bolin, \& Houston, 1974). The discipline problems examined included AWOL and all other offenses punishable under the provisions of the Uniform Code of Military Justice (UCMJ). In addition to these official forms of disciplinary infraction, the study included behavior rated by the platoon sergeants as insubordinate or recalcitrant.

The following research questions were posed:

1. What is the predictive validity of the identification instruments? 
2. Does use of instruments in the referral process reduce discipline failure?

3. Does referral for interview reduce discipline failure?

\section{METHOD}

The experiment was conducted at an Army Training Center in companies with new fills of men between 1 June and 30 November 1972. Among companies meeting the criterion, 5,333 men from 36 companies furnished sufficiently complete information for inclusion in the report. Because the experimental procedures were identical for all companies, the data were pooled into a single sample.

The research involved five phases:

1. Assignment of individuals to treatment conditions;

2. Conduct of interviews and other follow-up procedures;

3. Gathering of criterion data:

4. Further processing of control group data; and

5. Dàà analysis.

The first three phases occurred at the post, and the last two were completed at the Army Research Institute (ARI).

\section{Assignment of Individuals to Treatment Conditions}

At the beginning of $\mathrm{BCT}$, all participants completed both the TJTA and the $B O Q-72$. Participants then were randomly divided into three samples: the TJTA sample, the BOQ sample, and the control sample. Within the TJTA sample, the TJTA's alone were scored; this yielded two groups: the TJTA high-risk group--those who met the criteria for the AWOL syndrome--and the TJTA reduced-risk group. The former group was referred for interview; the latter was not. Scoring of the $B O Q-72$, in the $B O Q$ sample, also resulted in the formation of two groups: a BOQ high-risk group, referred for interview, and a $B O Q$ reduced-risk group which was not referred.

Random assignment (rather than scoring of protocols) led to the formation of two groups from the control sample. The 108 referred for interview constituted the control-interview group; the remaining $90 \%$ constituted the control-noninterview group. 
In summary, the TJTA, BOQ, and control samples were divided into six groups by the scoring and referral procedures. The TJTA high-risk, BOQ high-risk, and control-interview groups were referred for interview. The remaining three groups (the reduced-risk TJTA, reduced-risk BOQ, and the control-noninterview groups) were not referred. A pictorial representation of the process and its results is shown in Figure 1.

\section{Conduct of Interviews and Follow-Up A.ctions}

After the testing, assignment, and scoring procedures were completed, each company commander was given a list of individuals to interview and the protocols of these men. The list contained the names of soldiers to interview and their group designations, i.e., high-risk TJTA, high-risk BOQ, or control-interview. Although both protccols were available to a commander for each man, only the appropriate one was scored, i.e., the TJTA for the TJTA high-risk group; the BOQ-72 for the BOQ high-risk group; and neither for the control-interview group.

To aid the commanders, a special manual (PT 4887) on the art of conducting interviews was prepared. In addition, an effort was made to teach some commanders how to conduct interviews; however, it was not possible to provide this training to many commanders. When the help was provided, it consisted of individual and group discussions and live demonstrations of interviewing techniques.

Throughout this report, the phrase "referred for interview" is used to describe what happened to the men who appeared on the commanders' lists. It is difficult to determine from the data whether, in fact, the men were interviewed, what types of interviews they received, and what types of follow-up actions occurred. This subject is treated more fully in the discussion section.

\section{Gathering of Criterion Data}

The criterion data consisted of disciplinary infractions recorded on each participant at the end of BCT. The data came from records available at company, battalion, brigade, and post levels, and also from a special end-of-cycle rating form administered as part of the research. (The form is called "the Training Performance Rating," PT 4878; instructions are provided for its use in PT 4880.)

For the present report, this information was used to reduce the sample to three classes of men:

1. Those who were AWOL or whose actions resulted in a recorded punishment under the UCMJ. This punishment could be "Article $15^{\prime} \mathrm{s}^{\prime}$ conviction by special or general court martial, or separation from the service under other than honorable conditions. 


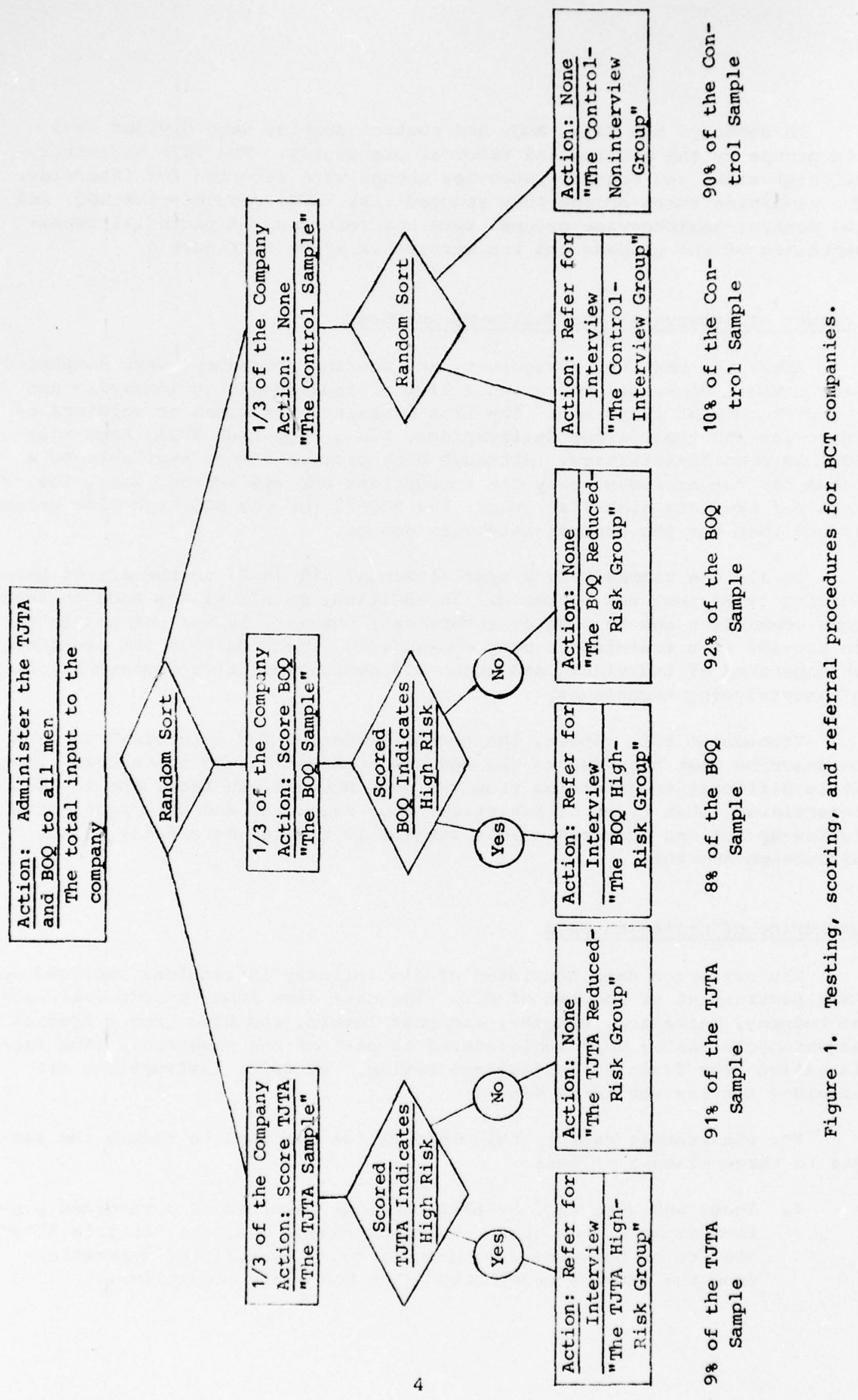


2. Those who were rated by their platoon sergeants as insubordinate or recalcitrant but who had no official record.

3. Those who had no such punishment or rating.

These three classes were "official," "marginal," and "clean," respectively.

\section{Further Processing of the Control Group}

Once data from the post had been returned, the TJTA's and BOQ-72's for each man in the control-noninterview group were scored. The independent scoring of the prediction instruments by the researchers resulted in four subsamples: a high-risk and a reduced-risk group for each of the two instruments. However, because both instruments were scored for the same persons, the TUTA and $\mathrm{BOQ}$ groups were not independent from one another. 1 The four subsamples or groups were called, respectively,

1. TJTA high-risk,

2. TJTA reduced-risk,

3. BOQ high-risk, and

4. BOQ reduce-risk noninterview groups.

Figure 2 is a pictorial representation of the process that produced them.

\section{Analysis of the Data}

The data were considered nominal in level with an underlying continuous distribution. Analytic techniques were chosen accordingly. Chisquare was used to test for differences in discipline outcomes for different groups. Tetrachoric correlation was used to show the strength of relationships.

The typical data display used to answer research questions was a $2 \times 3$ table. For example, to answer the question of how predictive of discipline failure the TJTA was, the discipline outcomes (official, marginal, and clean) for the TJTA high-risk and the TJTA reduced-risk noninterview groups were displayed and analyzed.

\footnotetext{
In fact, the scores on the two instruments were moderately correlated with one another in the control-noninterview group $\left(r_{\text {tet }}=.26\right)$.
} 


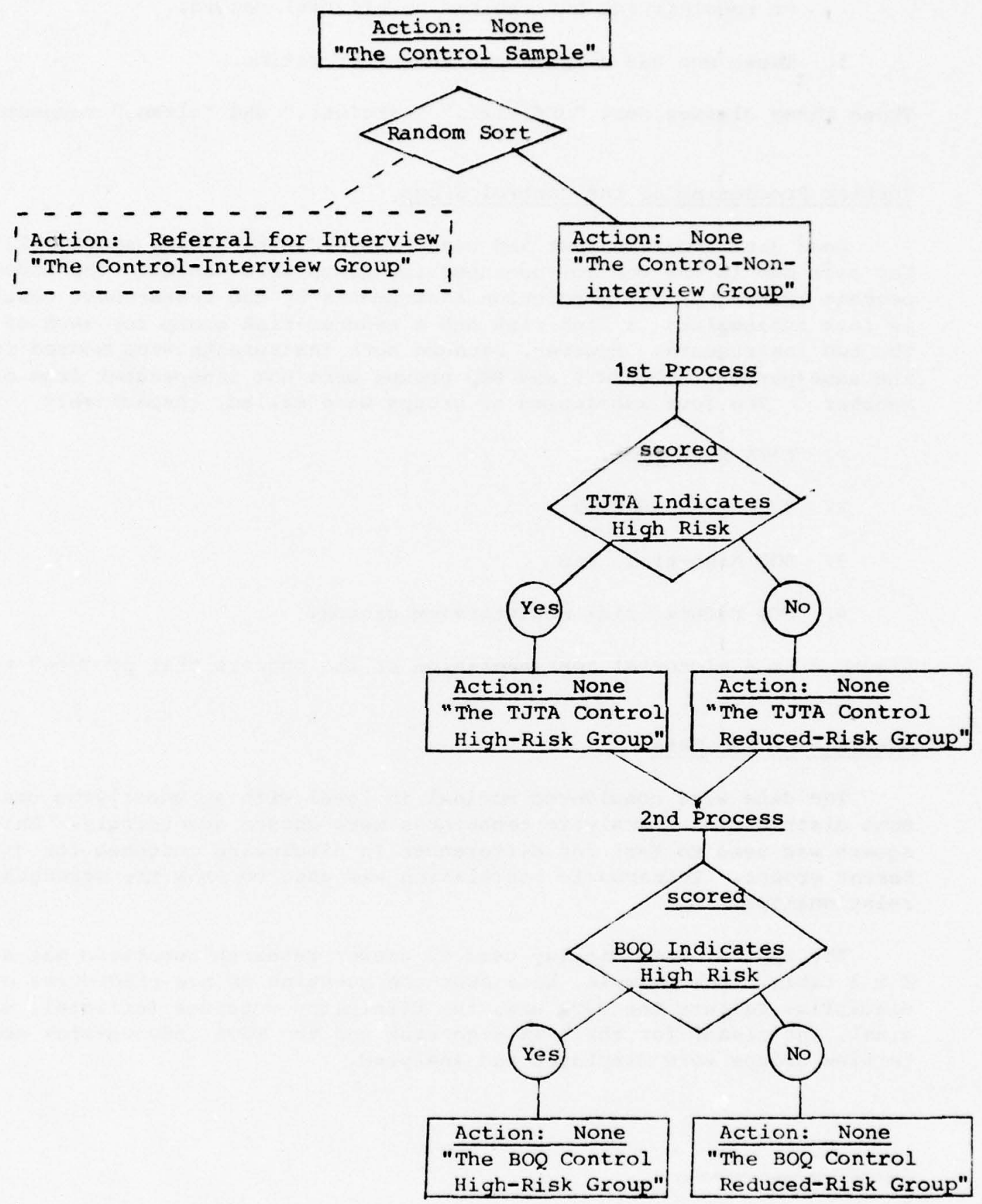

Fiqure 2. Results of processing the control-noninterview group. 
To maximize the information available in these $2 \times 3$ tables, the chi-square analyses were divided into orthogonal partitions (Castellan, 1965). Two separate chi-squares were computed: one comparing the two groups in terms of clean versus marginal outcomes, and a separate comparison of these two outcomes combined and contrasted with the official outcome. An overall chi-square for each analysis was also obtained by combining the two partitions and comparing the obtained value with that expected for an analysis with 2 degrees of freedom.

The use of tetrachoric correlations also depended on reducing the $2 \times 3$ tables to $2 \times 2$ displays before computing the correlations. Because the discipline criterion was considered continuous, the method of collapsing was arbitrary. Collapsing the marginal and official categories yielded the most stable estimates and was therefore used. Computations were based on Thurstone's tables (Cheshire, Saffir, \& Thurstone, 1933).

For some analyses, three dimensions were present: scores on a predictor instrument, referral status, and discipline outcome. For these analyses, the resulting $2 \times 2 \times 3$ tables were partitioned into two $2 \times$ $2 \times 2$ tables and analyzed using snedecor's (1946) procedure.

\section{RESULTS}

There were three research questions:

1. What is the predictive validity of the identification instruments?

2. Does use of instruments in the referral process reduce discipline failure?

3. Does referral for interview, in the absence of any instruments, reduce discipline failure?

For two of the questions, separate analyses are provided for each of the two instruments involved.

\section{How Predictive of Discipline Failure Are the Two Instruments?}

The first research question--what is the predictive validity of the i.dentification instruments--required separate analyses for each of the two instruments. These analyses, using the control-noninterview group, appear in Table 1. 


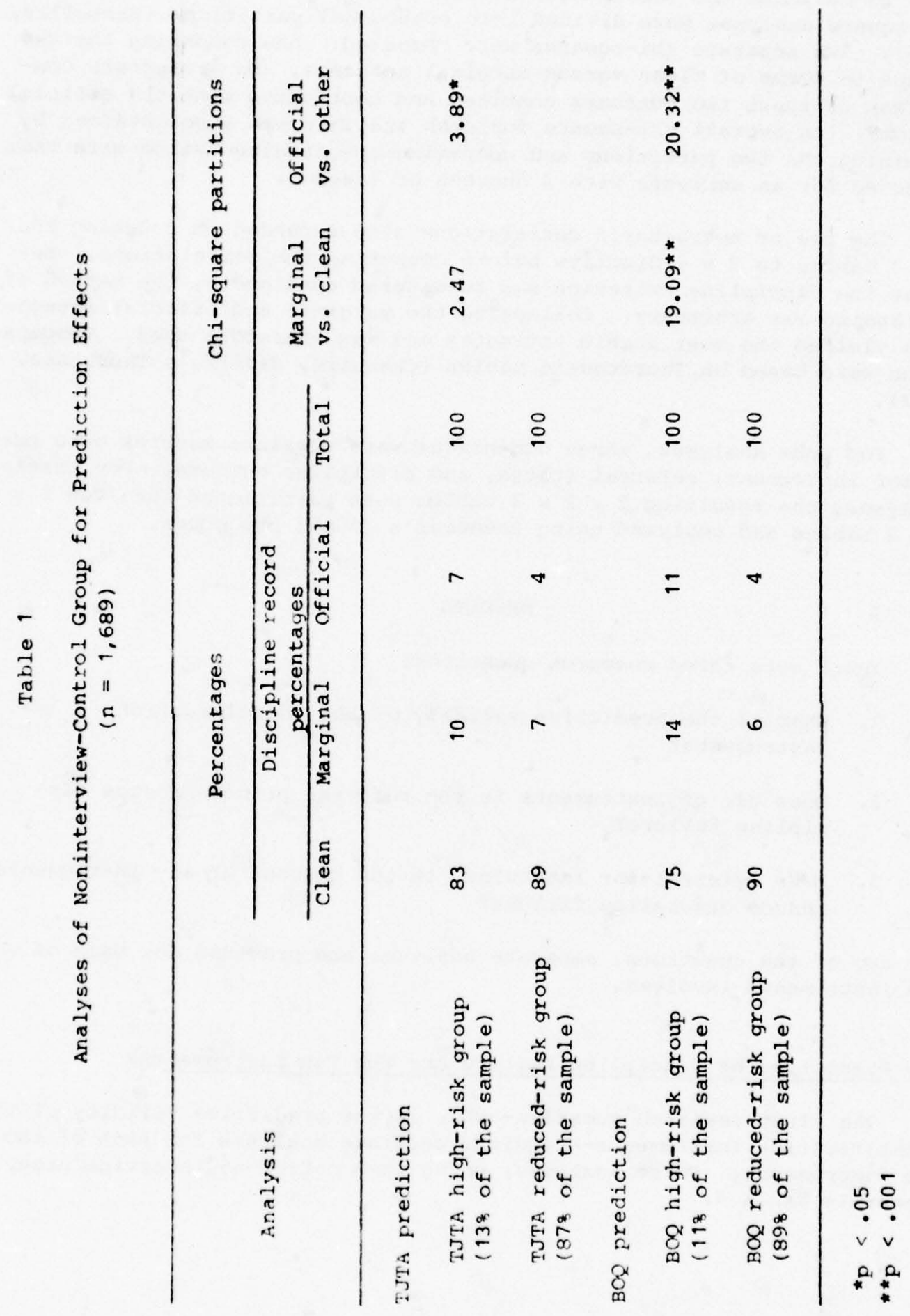


How Predictive Is the TJTA? AWOL syndrome scoring of the TJTA was related to whether a man got into trouble (the marginal and clean versus official comparison) but not to how he was rated (the marginal versus clean comparison). However, the size of the relationship between TJTA scores and discipline failure in BCT was small $\left(r_{\text {tet }}=.12\right)$.

How Predictive Is the $B O Q-72$ ? The $B O Q-72$ was related to all aspects of discipline. Both partitions of chi-square and the tetrachoric correlation for the data in Table $1\left(x_{\text {tet }}=.32\right)$ were significantly different from chance.

\section{How Effective Is the Use of Instruments in the Referral Process?}

Because the answer to the question may depend upon the instrument being used, separate analyses are provided for the TJTA and BOQ identification-referral systems.

The Effect of TJTA Referral Upon Discipline Rates. The soldiers referred for interview using the TJTA were different from other men in two ways: they scored in the high-risk group and they received special attention. Table 2 shows the degree of relationship that occurs when these two conditions are compounded. Subsequent analyses show what occurs when the two conditions are unraveled.

Scores on the TJTA were related to discipline failure for one partition of chi-square (official versus other) but not the other (marginal versus clean). The tetrachoric correlation was also significant $\left(r_{\text {tet }}=.20\right)$. The degree of relationship between scores and discipline failure appears stronger here than when scores did not lead to referral (Table 1 ).

To sort out the effects of risk and referral, it was necessary to compare the data in Table 1 (where risk alone was operative) with the data in Table 2 (where both risk and referral were operative). To make this comparison, Snedecor's (1946) procedures for computing $2 \times 2 \times 2$ chi-squares were applied to orthogonally partitioned data from each table. Table 3 presents the results of these analyses for different levels of risk (high-versus reduced-risk), referral status (referred versus not referred), and discipline outcomes (marginal versus clean, and official versus other).

Referral based upon TJTA scores had no effect on platoon sergeants' ratings (the clean versus marginal comparison). However, it did affect the official punishment rate (the official versus other comparison). Use of the TJTA to refer men for interview is counterproductive, i.e., the number of high-risk men punished increased from 78 (Table 1) to 128 (Table 2). 


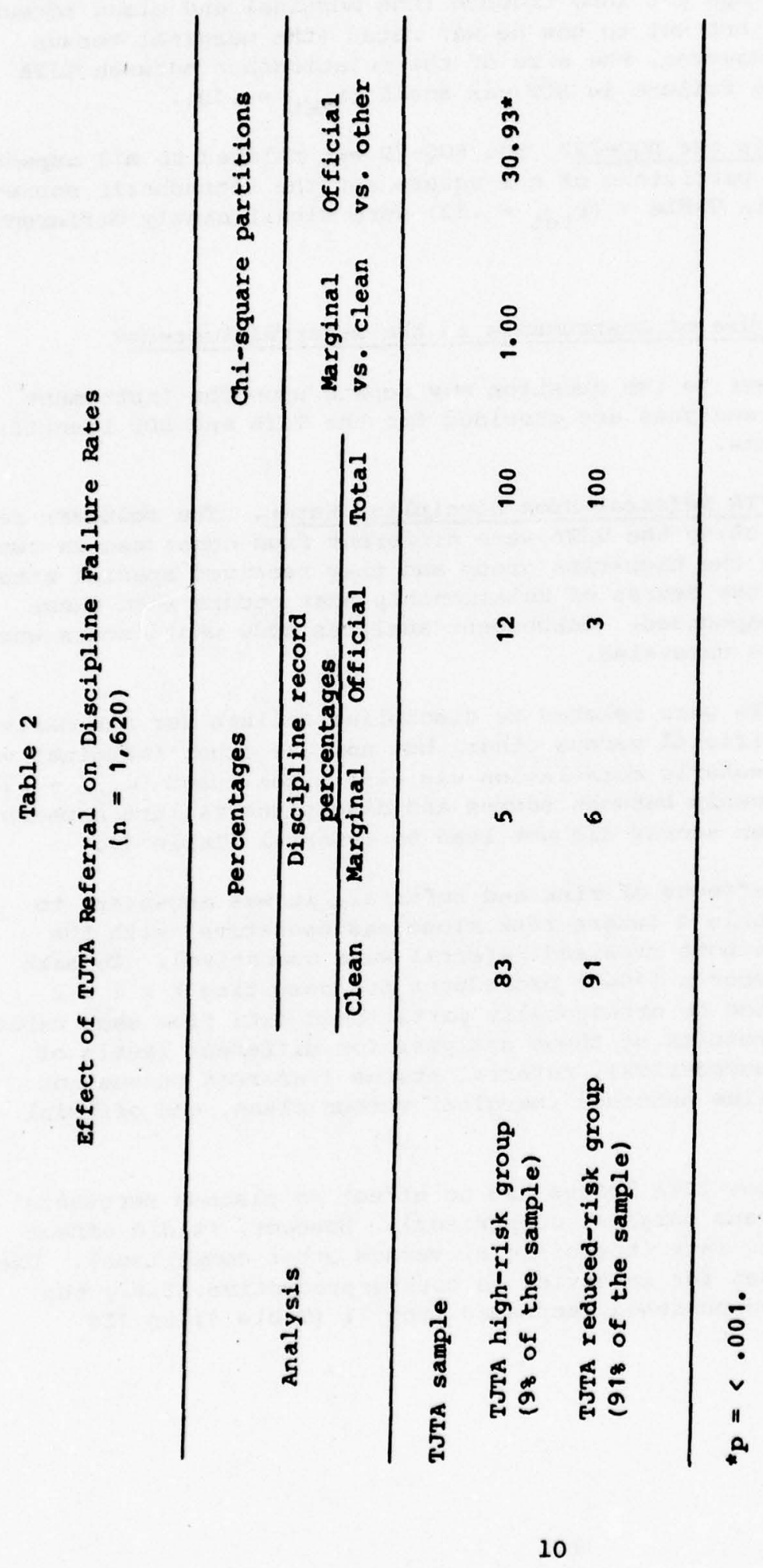


Table 3

Relationship Between Risk, Outcome, and Referral

for the TJTA

$(n=3,309)$

Analysis

Chi-square

Degrees of freedom

Probability

$\begin{array}{lrcr}\text { Marginal vs. clean } & .67 & 1 & \text { n.s. } \\ \text { official vs. other } & 4.35 & 1 & .05\end{array}$

The Effect of BOQ Referral upon Discipline Rates. As in the case of the TJTA identification-referral system, this portion of the research question can be analyzed only by comparing the discipline experience of two groups: one where risk alone is operative (the control-noninterview group) and one where both risk and referral are operative (the BOQ sample). Table 4 shows what occurred in the BOQ sample.

Table 4 indicates that in the $B O Q$ sample (as in the control-noninterview sample in Table 1), BOQ-72 scores were related to all aspects of discipline in BCT. That is, both partitions of chi-square and the tetrachoric correlation for these data $\left(r_{\text {tet }}=.37\right)$ were significantly different from chance. This is in contrast to the findings for the TJTA where significant differences were not always present (Table 2).

Table 5, like Table 3, shows the effects of using an instrument in the referral process. Again, the table presents the analyses for two types of risk, two types of treatment, and three discipline outcomes.

Use of the $B O Q-72$ to refer men for interview had no effect upon discipline failure.

\section{How Effective Is Referral for Interview Alone?}

The final research question--does referral for interview (without instruments) decrease discipline failure?--can be answered by contrasting the disciplinary outcomes for men randomly referred for interview (the control-interview group) with those who were not referred (the control noninterview group). Table 6 shows this comparison. 


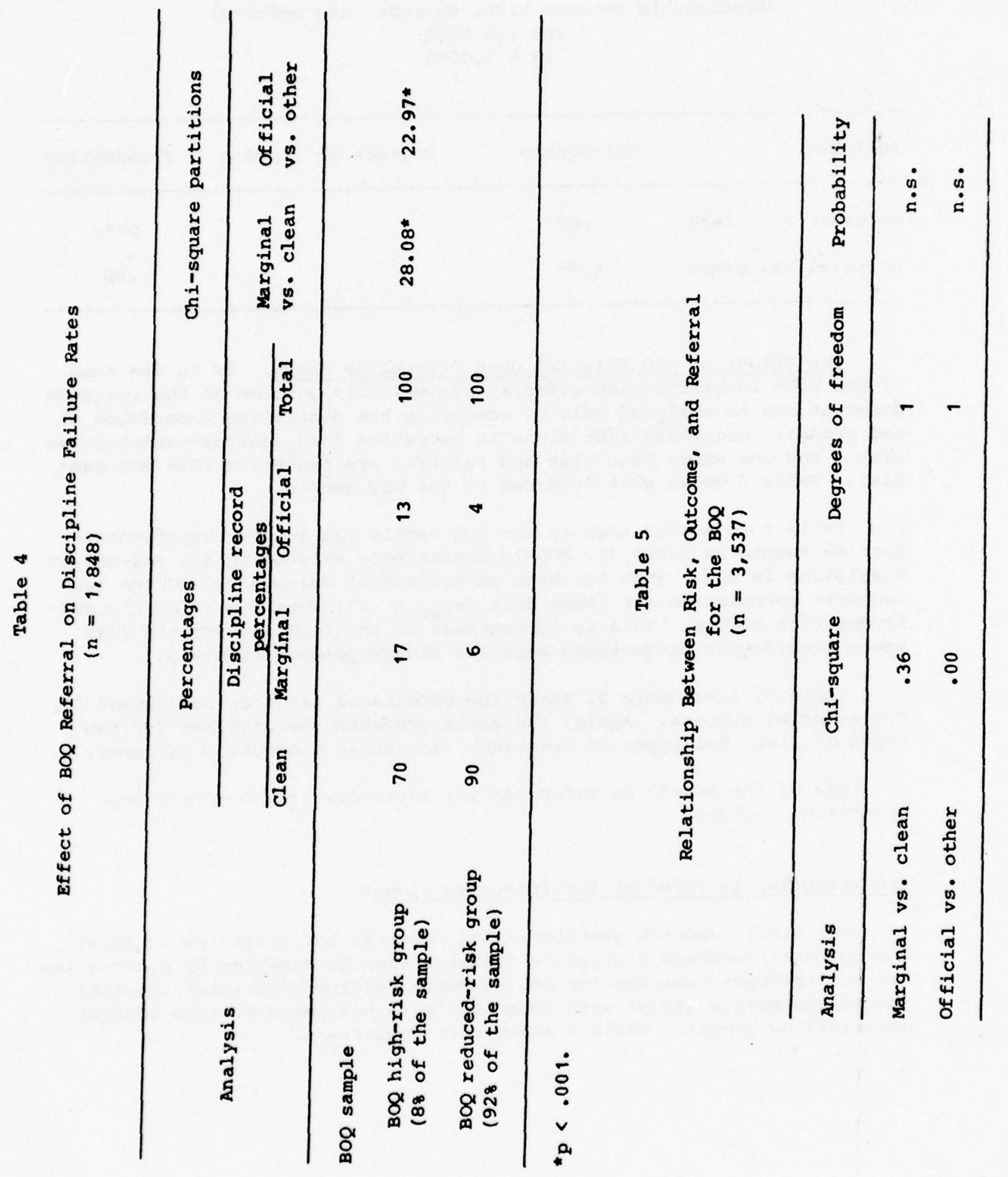




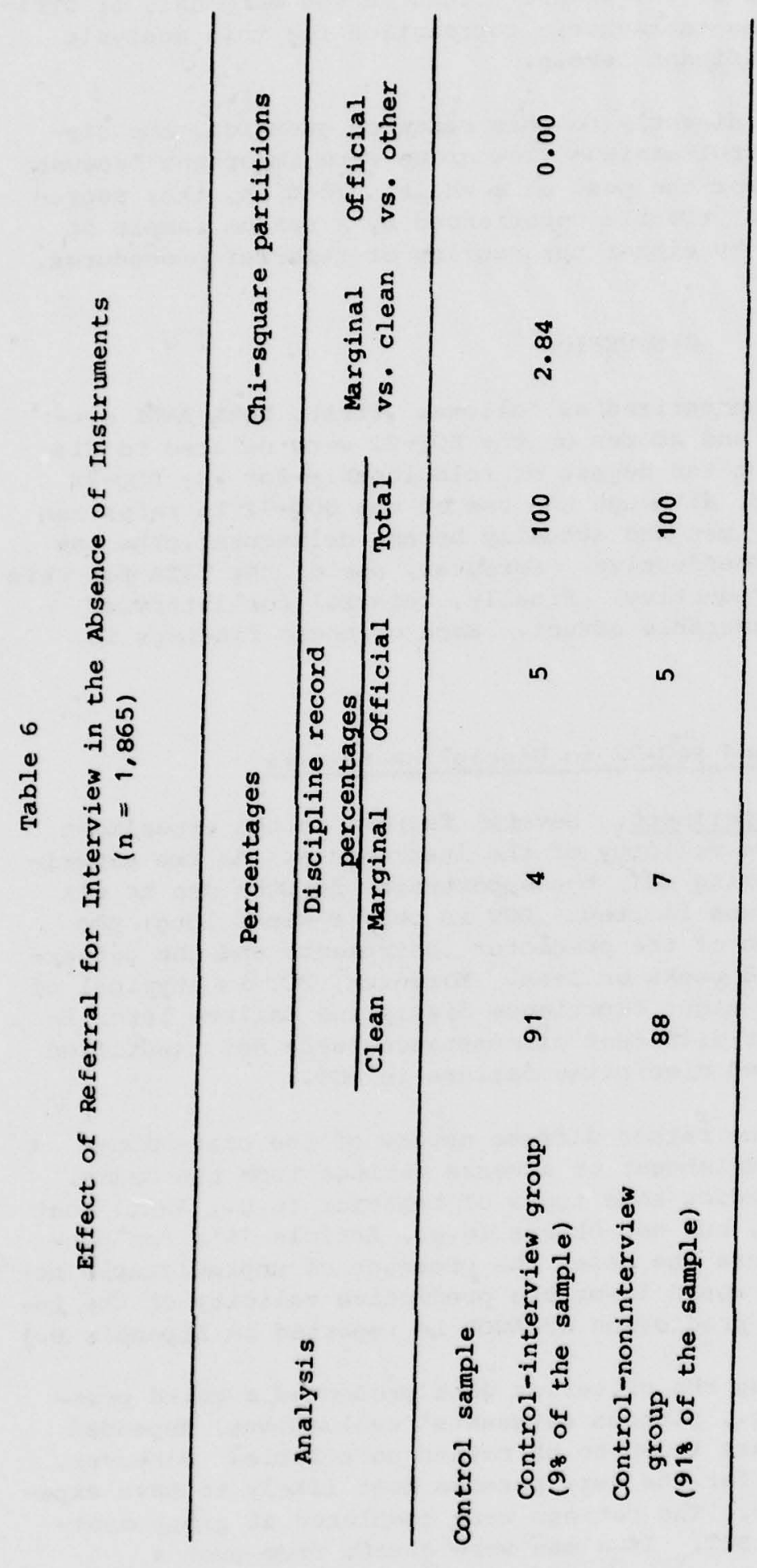


Random selection for interview had no effect upon discipline failure in BCT. Neither partition of chi-square (clean versus marginal, or official versus other), nor the tetrachoric correlation for this analysis

$\left(r_{\text {tet }}=.08\right)$ reached significant levels.

Al though not related directly to this research question, the discipline rates for the control-noninterview group were important because they were the base rates for the post as a whole. That is, they represented the expected rate of trouble experienced by a random sample of men not affected directly by either the scoring or referral procedures.

\section{DISCUSSION}

The findings can be summarized as follows. First, both AWoL syndrome scoring of the TJTA and scores on the BOQ-72 were related to discipline failure in BCT, but the degree of relationship for the BOQ-72 was much stronger. Second, although the use of the BOQ-72 to refer men for interview yielded more men who actually became delinquent, the use of either instrument was ineffective. Moreover, use of the TJTA for this purpose was even counterproductive. Finally, referral for interview (using no test) had no measurable effect. Each of these findings is discussed further.

\section{Relationship of the TUTA and BOQ-72 to Discipline Failure}

Limitations of the Experiment. Several factors in the experiment probably limited predictive validity of the instruments. As the experiment was conducted only during BCT, the opportunity for the men to get into some form of trouble was limited. BCT is only 8 weeks long; the time between administration of the predictor instruments and the gathering of criterion data was 8 weeks or less. Moreover, BCT is atypical of time in the Army. Men who might experience discipline failure later in their Army careers or under different circumstances were not identified unless they also experienced discipline failure in BCT.

A second factor was the rather diffuse nature of the criterion-any behavior that evoked punishment or adverse ratings from the cadre. Either instrument could predict some types of behavior (e.g.., AWOL) that were part of the criterion, but not othexs (e.g., Article 15's for nonAWOL offenses). If this were the case, the presence of unpredictable behavior(s) in the criterion would lower the predictive validity of the instrument(s). (The test of prediction of AWOL is reported in Appendix B.)

The method of gathering the criterion data presented a third problem. Much of the data (e.g., platoon sergeants' evaluations) depended upon rating scales, which are known to be rather unreliable. Moreover, ratings were often missing for the very persons most likely to have experienced discipline failures. The ratings were completed at group meetings at or near the end of BCT. If a man were absent from such a 
meeting because he was AWOL, in the stockade awaiting punishment, or recycled due to AWOL, his rating might have been omitted. Data drawn from brigade or post records (e.g., courts martial and discharges under less than honorable conditions) were more complete.

Finally, instruments like the TJTA and $\mathrm{BOQ}$, which focus upon characteristics of the man only, probably can never attain high validity. The instruments simply do not measure important variables such as characteristics of company leaders, atmosphere of the company (e.g., racial tensions, pressures to use drugs, etc), Army policies, and opportunities to engage in deviant behaviors. All these considerations affect the probability that punishable acts will occur and that such acts will result in punishment of adverse ratings. Also several studies have shown that unit delinquency rates are related to characteristics of units and their leaders (McCubbin et al., 1971; Hart, in press).

Discussion of the TJTA. It is not surprising that AWOL syndrome scoring of the TJTA was only weakly related to discipline failure in BCT. The scoring system was designed to differentiate between two groups of stockade prisoners: those who were incarcerated for AWOL offenses and those who were there for other reasons. It would be remarkable if the same scoring system also differentiated between basic trainees who got into trouble in BCT and those who did not, because this would mean that the same characteristics were common to these quite different groups. Berbiglia's use of the TJTA strongly implies that he believed the instrument could differentiate; however, he does not present supporting data. Instead, Berbiglia offers some indirect proof of the validity of the instrument. Discipline failure rates dropped in those battalions where Berbiglia's program was in effect. Because the TJTA was part of that program, one could argue that the instrument has some validity. This reasoning is not compelling.

Several subsequent research projects (reviewed in Appendix B) show that the TJTA does not (a) effectively differentiate between AWOL and non-AWOL prisoners (Fraas \& Fox, 1972); (b) effectively predict discipline failure in BCT (Bell, Bolin, Houston, \& Kristiansen, 1973); or (c) effectively predict AWOL in BCT (see Appendix B).

Although by no means the only problem, part of the difficulty of predicting AWOL using the AWOL syndrome approach is that the scoring system selects more men for the high-risk group (138 of the sample) than actually get into trouble. Only about 48 of the men were in any form of official trouble, and only about 28 of the men went AWOL. Thus there is a built-in inflation in the number of false positives, i.e., men who are predicted to go AWOL but who, in fact, do not. Changing the cutting scores-and thus reducing the proportion of false positives--on the TJTA might result in a better instrument, but several fundamental problems would still remain. First, there is no research guide to help determine which scale scores to alter. Second, serious questions exist concerning whether or not the scoring system has intrinsic validity. Finally, a better instrument already exists: the $\mathrm{BOQ}-72$. 
Discussion of the $B O Q-72$. Previous research shows that the $B O Q-72$ items can predict disciplinary failure in BCT/AIT (Larson \& Kristiansen, 1969) and that the items are even more predictive if separate cutting scores are used for young dropouts (Bell et al., 1974). Thus, it should come as no surprise to find that the BOQ-72 is predictive of discipline failure in BCT. What is surprising is the range of disciplinary events to which the BOQ-72 is related. For example, Table 1 shows that the $B O Q-72$ is related to platoon sergeants' ratings and to official discipline. Subsequent analyses of data from the control-noninterview group show that the $\mathrm{BOQ}-72$ is also predictive of AWOL, Article 15's, Article 15 's for AWOL, and Article 15's for non-AWOL offenses. Although all these relationships are statistically significant, the magnitude of the obtained statistics places very definite limitations upon the number of administrative decisions that can be made on the basis of BOQ-72 scores.

For example, the $B O Q-72$ might be useful in an early referral program because the costs of interviewing are low and there is ample opportunity to interview or take other appropriate actions with men not identified by the instrument. It is doubtful, however, that the instrument could be justified in a more costly program (e.g.. using professionally trained counselors), because the majority of men referred to such a program would not actually need the services (see Table 1). More importantly, the BoQ-72 could not be the ultimate screen to eliminate men from service at the point of entry. The BOQ-72 would eliminate many more "good" men than "bad" ones and would leave more "bad" men in the Army than would be eliminated.

Although additional research might refine the $\mathrm{BOQ}-72$, it would probably remain insufficiently predictive for practical purposes. The instrument focuses only upon characteristics of individuals and ignores the situational variables. These, in turn, are probably subject to a great deal of chance variation. If discipline failures are to be identified and reduced, additional research to determine the relevant situational variables is needed.

General Discussion and Conclusions. The BOQ-72 is clearly superior to the TJTA as a predictor of disciplinary failure in BCT. The BOQ-72 is also superior in other respects. First, it is shorter (i.e., 25 versus 180 items) and, consequently, easier and faster to administer. Second, the $B O Q-72$ has a simpler scoring system $(i . e .$, one scoring key rather than six). Third, the $B O Q-72$ is a good interview guide, because the answer sheet contains the questions as well as the responses, and the items on the $\mathrm{BOQ}-72$ are arranged in topical areas. (In contrast, the TJTA has a separate, machine-scorable answer sheet. On return to the commanders, the sheet has only the pencil marks made by the respondents and a red check for each scale within the range required by the AWOL syndrome system.) Finally, there is the matter of cost--no small factor in the use of an instrument for any post-wide or Army-wide experiment or program. The Army owns the BOQ-72 but must pay royalties for each TJTA it uses. All these justifications support the conclusion that the BOQ-72 is at present the instrument of choice for discipline research. 
The Role of Identification and Referral Systems in Reducing Discipline Failure system:

Several assumptions are made in adopting any identification-referral

1. That what is needed is a quick means of differentiating soldiers who need help from those who do not,

2. That the differentiation is valid, and

3. That effective help can and will be provided to the identified men.

The TJTA and BOQ systems met the first assumption. The tests were administered shortly after trainees were assigned to their units. The systems were scored and entered into the commanders' referral lists within another 24 hours. But neither system met the crucial second assumption. In both systems, most of the men referred were unlikely to have experienced discipline failure (Table 1) or to have needed special attention. Also, neither system met the third assumption. The referred men were not less likely to experience discipline failure. In fact, there was a slight increase in the probability that men referred by the TJTA would get into more trouble than if no intervention had occurred!

Why the systems did not work--and why the TJTA system proved counterproductive--is not entirely clear. But some data are suggestive, and some speculation is possible.

Why the Systems Did not Work. When (a) a soldier engages in some form of deviant behavior, (b) the behavior is observed by, or reported to, someone in authority, and (c) the act then leads to a reaction by someone in authority (i.e., a punishment or an adverse rating), a discipline failure is recorded.

Successful intervention should be directed toward decreasing the probability that soldiers will behave in a deviant manner. Although there is ample evidence that effective psychotherapy can accomplish this goal, it has not been proved that the type of interviewing suggested in the manual, PT 4887, will yield similar results. In this experiment, interviewing might also have decreased discipline failure by decreasing the probability that a man would be observed or punished; however, this was not likely. Persons largely unaffected by the interviews--the platoon sergeants--did most of the observing and all of the rating. Although company commanders have some flexibility in deciding whether or not to punish men, the policies of the Army and the battalion commanders largely determine what will occur. Thus, it could be argued that any increases in discipline failure following referral for interview occurred because the commanders did not reduce the probability that men would engage in deviant behavior, or because the commanders did not change the probability t..at such behavior would be observed and punished. Both are probably 
true; the question still arises, "Would successful use of the procedures outlined in PT 4887 have decreased the discipline failure?" We do not know, as the bulk of the evidence available shows that these procedures were not applied consistently.

The administrative and experimental controls were not sufficiently formaliz 1 for us to be certain about events after men were referred. However, considerable evidence suggests that often no interviews occurred, and that when they did occur, the interviews did not follow procedures suggested in the interview manual.

For example, the instructions state that protocol should be divided into sections by having lines drawn between certain questions. The instructions also state that the commander should summarive the trainees' feelings toward the events represented by those questions by writing notes in the margin. Although these instructions are clearly part of the procedures for conducting interviews with men in the $B O Q$ and control-interview groups, only 10 of the 326 protocols in the two groups had any such markings. Furthermore, the researchers seldom encountered commanders who were aware that any "special" style of interview was required for this research program, despite the efforts of the researchers to keep commanders informed about what was expected.

Several factors may have contributed to the commanders' low utilization of interview procedures. First, it was difficult for the small research staff, which was located some distance from the post, to orient and $t r$ in all the commanders. This problem was further compounded by the turnover of commanders, which occurred throughout the research. Second, commanders are busy people who often work 10-16 hours a day, 6-7 days a week, during the time BCT is being conducted. Therefore, the commanders might not read manuals and might provide pro forma interviews, or no interviews at all. Finally, the commanders might not have followed the procedures because they did not believe that they would work. Commanders generally have their own ideas about how troops should be interviewed; these ideas do not always coincide with the methods suggested in this research.

The labels TJTA and BOQ "high risk" may have conditioned the interviews that soldiers received and the additional treatment offered. For example, the researchers noticed that the officers and NCO's tended to think of the TJTA and $B O Q-72$ as tests the men passed or failed.

The terms "Taylor-Johnson failure" and "BOQ failure" appeared often In the vocabulary of the company leaders and were even used as epithets hurled at the unlucky trainees whose names appeared under appropriate headings on the referral lists. Some commanders stated that, although they tried to be objective in dealing with trainees, the labels did influence the type and severity of punishment. It is unclear whether the labeling was responsible for differences in discipline failure rates for men referred under the TJTA or BOQ systems. In other situations, 1abelIng has produced adverse effects through the mechanism of scapegoating. 
Those in authority are more likely to observe and punish those identified by an adverse label. Labeling may also produce self-fulfilling prophecy effects. Both those in authority and those who are labeled come to accept and act on the presumed validity of the labels.

The most likely explanation of the TJTA's counterproductive effect. is its wider degree of acceptance among the men and leaders. It would probably have been more subject to a self-fulfilling prophecy or scapegoating effect. Personnel at Fort Polk, La., where the AWOL syndrome approach was first used, were convinced of the value of the instrument as a tool for reducing AWOL. The TJTA was the cornerstone of the ongoing, post-wide program; its labels were thus guaranteed an impact. The $B O Q-72$ was received only as an experimental instrument being tried by an outside agency.

Random Selection for Interview Had no Effect. Why random selection did not reduce discipline failure rates is not immediately apparent from the data. Probably two opposing forces operated to produce these results. Improvements failed to occur because commanders were not properly trained and often did not apply the interview procedures. But also, the rates did not increase because the label control was relatively neutral and did not lead to scapegoating or self-fulfilling prophecy. Further research could test the validity of this speculation.

\section{Conclusions and Suggestions for Further Research}

The AWOL syndrome scoring system is not a good predictor of disciplinary failure in BCT. The $B O Q-72$ is predictive of all of the disciplinary criteria. Thus, the BOQ-72 is the instrument of choice for future research efforts in the field of discipline. However, its present level of validity severely limits its use as an administrative tool. Further research could refine the BOQ-72, but it is doubtful that any instrument focusing exclusively upon individual characteristics would be administratively practical or useful. Further efforts should be directed toward (a) learning more about situational variables that impact on discipline failure, and (b) improving treatment systems.

Plans are underway to conduct just such a demonstration study. Researchers would be placed in training companies over an extended period of time to teach commanders how to conduct better interviews, and to learn more about the noninterview events that affect discipline failure in BC'T. In order to overcome the labeling problem, no protocols would be scored. Instead, commanders would be asked to interview a random portion of their men, using the $B O Q-72$ as an interview guide. It is hoped that the commanders would demonstrate to the entire company as a whole that they are approachable and concerned about personnel problems, and that their attitudes would lead to a decrease in discipline problems. If personnel become less fearful of the command, they might be more willing to refer themselves for interview and appropriate follow-up services before they get into trouble. Self-referrals are probably better than 
instrument-referrals for two reasons. First, given the low accuracy of the instruments, self-referred men are more likely than instrumentreferred men to actually need assistance. Second, and more important, self-referrals probably see problems with which they want assistance and are more motivated to improve and less likely to get into trouble. That, after all, is the point of having these systems in the first place. 
Bell, D. B., Bolin, S. F., \& Houston, T. J. Development of the Background and Opinion Questionnaire - 72. ARI Research Memorandum 74-13, 1974.

Bell, D. B., Bolin, S. F., Houston, T. J., \& Kristiansen, D. M. Predictions and Self-Fulfilling Prophecies of Axmy Discipline. Proceedings of the 81st Annual Convention of the American Psychological Association, 1973 .

Berbiglia, J. C. The AWOL Syndrome Supplement 3: Taylor-Johnson Temperament Analysis Manual. Los Angeles: Psychological Publications, 1971.

Castellan, N. J., Jr. On the Partitioning of Contingency Tables. Psych. Bull. 1965, 54 (5), 320-328.

Cheshire, L., Saffir, M., \& Thurstone, L. L. Computing Diagrams for the Tetrachoric Correlation Coefficient. Chicago: The University of Chicago Bookstore, 1933.

Fort Polk 1972 Post-Wide AWOL Seminar: Examination of the Past, Evaluation of the Present, and Recommendations for the Future. Fort Polk, La.: 1972.

Fraas, L. A., \& Fox, L. J. The Taylor-Johnson Temperament Analysis "AWOL Syndrome": A Further Evaluation. Fort Riley, Kans.: U.S. Army Correctional Training Facility, 1972.

Hart, R. J. Crime and Punishment in the Army. Journal of Personality and Social Psychology, in press.

Larson, E. E., Kristiansen, D. M. Prediction of Disciplinary Offenses Early in Army Service. ARI Technical Research Report 210, 1969.

McCubbin, H. I., et al. Leadership and situational factors related to AWOL: A research report. Fort Riley, Kans.: U.S. Army Correctional Training Facility, 1971.

Rollier, R. L. Fort Leonard wood AWOL and Desertion Study (FLWADS) Phase I. Fort Leonard Wood, Mo.: Headquarters, 3d Basic Training Brigade, U.S. Army Training Center Engineer, 1972.

Snedecor, G. W. Statistical Methods Applied to Experiments in Agriculture and Biology. Ames, Iowa: Iowa State College Press, 1946.

Taylor, M., Morrison, L. P., Morrison, W. L., \& Romoser, R. C. TaylorJohnson Temperament Analysis Manual. Los Angeles: Psychological Publications, 1968. 


\section{RECENT ARMY RESEARCH INSTITUTE PUBLICATIONS} ON MILITARY DELINQUENCY

Bauer, R. G., Stout, R. L., \& Holz, R. F. Predicting Military Delinquency. ARI Research Problem Review 76-4, August 1976.

Bauer, R. G., Stout, R. L., \& Holz, R. F. Developing a Conceptual and Predictive Model of Discipline in the U.S. Army. ARI Research Problem Review 76-5, september 1976.

Bell, D. B., Bolin, S. F., Houston, T. J., Kristiansen, D. M. Predictions and Self-Fulfilling Prophecies of Army Discipline. Proceedings of the Bist Annual Convention of the American Psychological Association, 1973, 743-744.

Bell, D, B., Kristlansen, D. M., \& Seeley, L. C. Initial considerations in the development of the Early Experience Questionnaire (EEQ). ARI Research Memorandum 74-10, July 1974.

Bell, D. B., Kristiansen, D. M., \& houston, T. J. Predictions and SelfFulfilling Prophecies of Army Discipline: A Follow-Up Evaluation. Paper presented at American Psychological Association Annual Convention, New Orleans, August 1974.

Bell, D. B., Bolin, S. F., \& Houston, T. J. Development of the Background and Opinion Questionnaire 72. ARI Research Memorandum 74-13, December 1974.

Bell, D. B., \& Holz, R. F. Summary of ARI Research on Military Delinquency. ARI Research Report 1185, June 1975. (Abstracted in APA Journal Supplement Abstract Service, 1976, 6, 16)

Be11, D. B., Houston, T. J. The Vietnam Bra Deserter: Characteristics of Unconvicted Army Deserters Participating in the Presidential Clemency Program. ARI Research Problem Review 76-6, July 1976.

Be11, D. B., Bell, B. W. Desertion and Antiwar Protest: Findings from the Ford Clemency Program, Armed Forces and Society, 1977, $\underline{3}(3)$, 433-443.

Be11. D. B. Characteristics of Participants in the DoD Special Discharge Review Program. ARI Research Problem Review 78-2, March 1978.

Be11. D. B. The Vietnam Era Deserter as Exile: The Canadian Experience. Paper presented at American Psychological Association Annual Convention, Toronto, August 1978. 
Cook, R. F., \& Morton, A. S. An Assessment of Drug Education-Prevention programs in the U.S. Army. ARI Technical Paper 261, January 1975.

Eckerman, W. C., Williams, J. R., \& Ramsay, D. A. Observations of Interrank Conflicts at the Company Level: Drug and Alcohol Abuse. ARI Research Memoranäum 75-15, December 1975.

Hart, R. J. The Relationship Between Perceived offense and Actual Discipiine Rates in the Military. ARI Research Memorandum 77-30, February 1978.

Hart, R. J. Crime and Punishment in the Army. Journal of Personality and Social Psychology, in press.

Hurst, P., Cook, R. F., \& Ramsay, D. A. Assessing the Prevalence of Illicit Drug Use in the Army. ARI Technical Paper 264, July 1975.

Ramsay, D. A. Summary of ARI Research on Drug and Alcohol Abuse. ARI Research Report 1186, May 1975. 
PREDICTION OF AWOL USING THE TJTA

In its original form, the AWOL syndrome scoring system for the Taylor Johnson Temperament Analysis or TJTA (Taylor, Morrison, Morrison, \& Romoser, 1968) was used to identify AWOL-prone soldiers. Several studies have addressed the question of the TJTA's efficiency as an AWOL predictor; they are reviewed in this appendix.

The Fraas and Fox Study

Fraas and Fox (1972) attempted to cross-validate Berbiglia's stockade research using 381 "trainees" at the U.S. Army Correctional Training Facility (CTF), Fort Riley, Kans. TJTA's administered to the men were scored according to Berbiglia's directions. The protocols were divided into three groups according to the offenses committed by the men:

1. AWOL offenses only ("AWOL"),

2. AWOL plus other offenses ("mixed"), and

3. Non-AWOL offenses only ("other").

Analysis of the Fraas and Fox data using partitioned chi-squares appears in Table $\mathrm{B}-1$.

The TJTA failed to differentiate AWOL or mixed prisoners from men incarcerated for non-AWOL offenses.

\section{The ARI Experiment}

The ARI experiment reported in this paper indicated that the TJTA was not a good predictor of broad categories of discipline failure. But the name of the scoring system suggests a more specialized use. Table B-2 presents an analysis of the predictive validity of the TJTA in this experiment for AWOL offenses only. Because of the small proportion of men reported AWOL, the phi coefficient has been substituted for the tetrachoric correlation as the measure of association.

AWOL syndrome scoring of the TJTA was related to AWOL offenses in BCT, but the degree of relationship was extremely weak. Apparently the TJTA is no better at predicting AWOL than discipline failure in general. (The beneficial effect of Berbiglia's program may not have been related to the identification process at all!) 


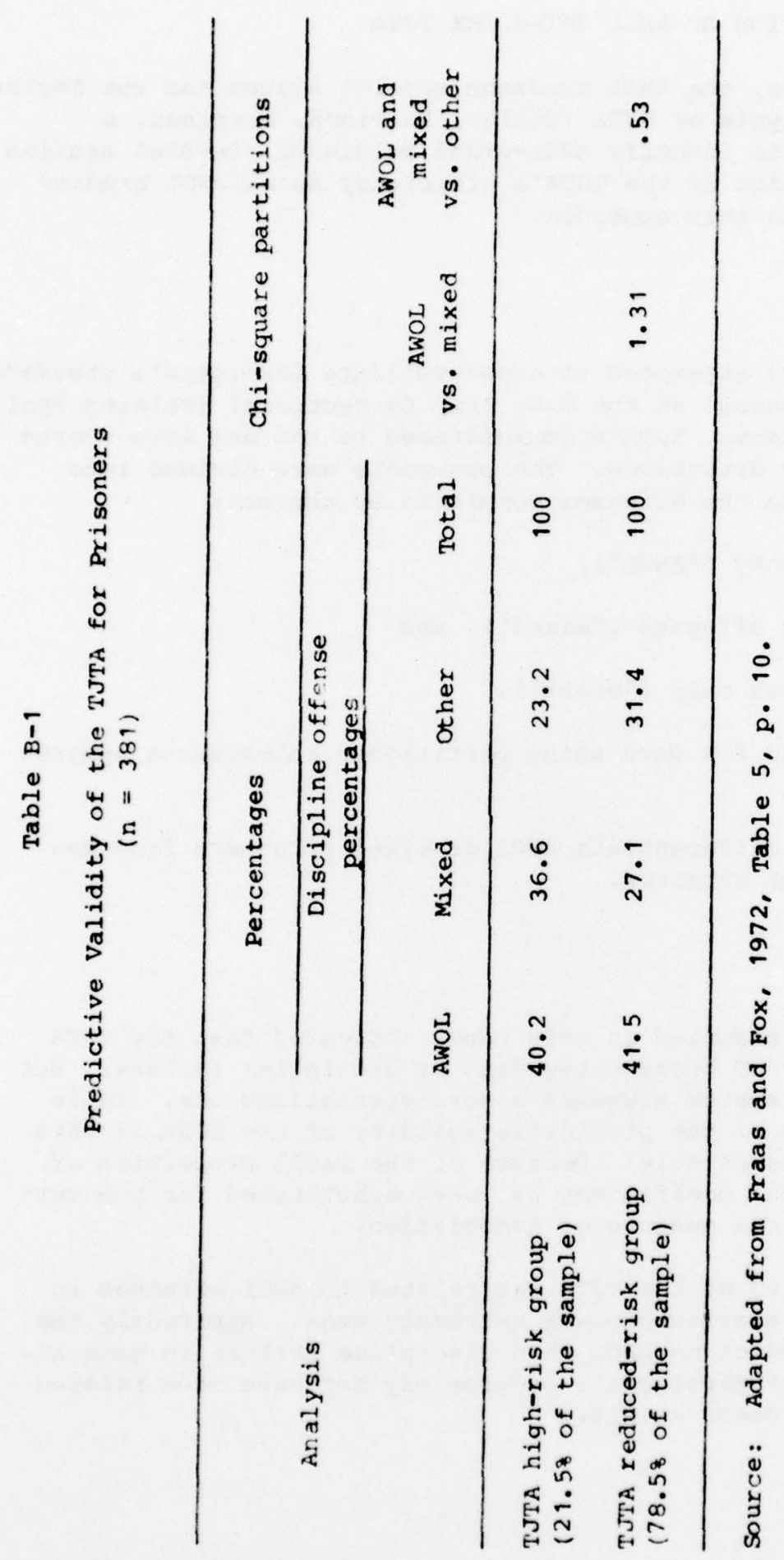


Table B-2

TJTA Prediction of AWOL for the ControlNoninterview Group

$(n=1,689)$

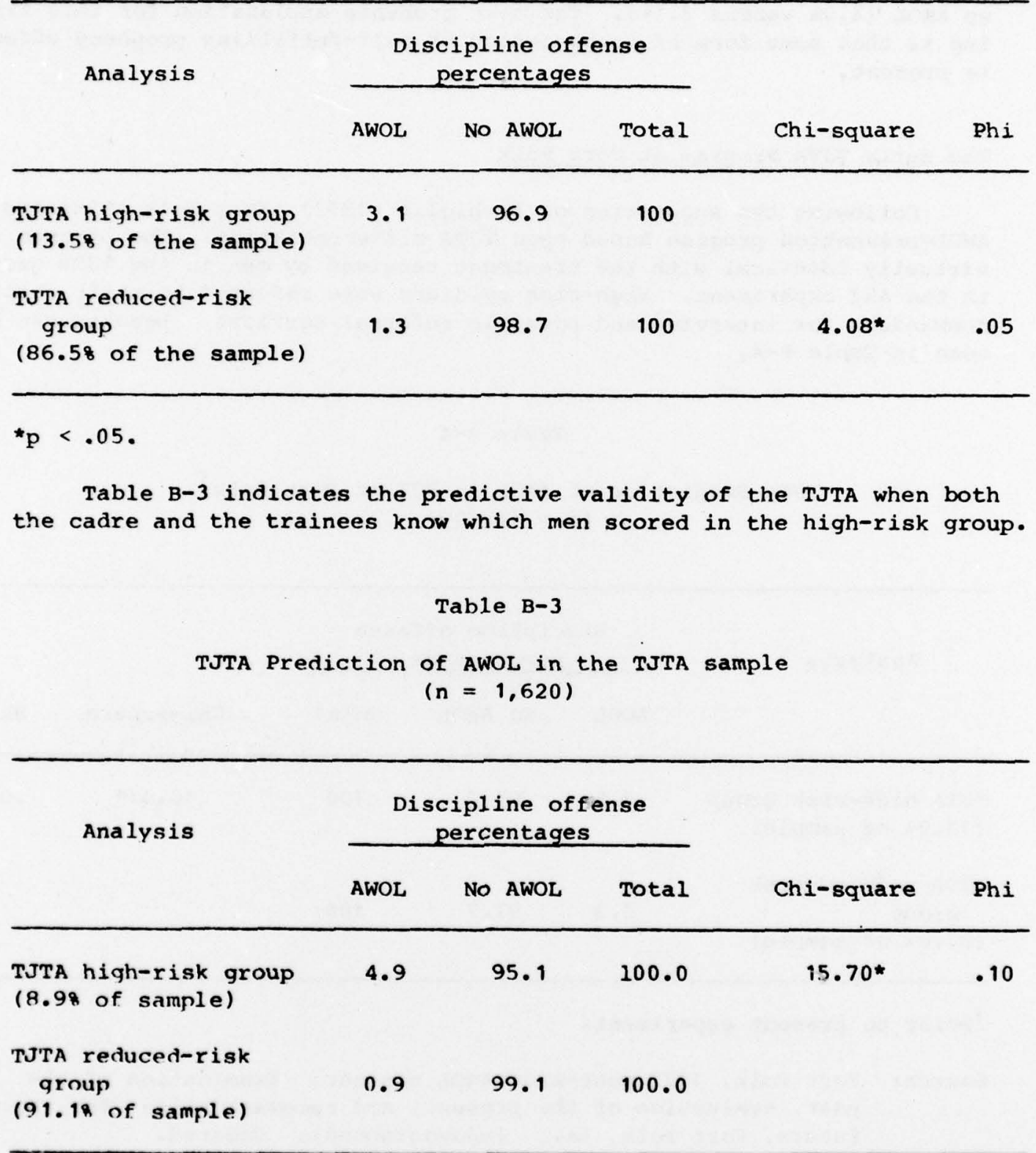

$* r<.001$. 
Scores on the TJTA are again significantly related to future AWOL behavior. Although it is true that the relationship between the scores and the behavior is small ( $\mathrm{phi}=.10$ ), the direction of the findings is somewhat alarming. Attempts by the cadre to prevent AWOL actually increase the probability that men identified as high-risk soldiers will go AWOL (4.98 versus 3.18 ). The most probable explanation for this finding is that some form of scapegoating or self-fulfilling prophecy effect is present.

The Early TJTA Program at Fort Polk

Following the suggestion of Berbiglia (1971), Fort Polk initiated an AWOL-prevention program based upon TJTA differentiation. The program was virtually identical with the treatment received by men in the TJTA group in the ARI experiment. High-risk soldiers were referred to their company commanders for interview and possible referral services. Results can be seen in Table $B-4$.

Table $B-4$

TJTA Prediction of AWOL in BCT at Fort Polk ${ }^{1}$

$(n=18,139)$

\begin{tabular}{|c|c|c|c|c|c|}
\hline \multirow[t]{2}{*}{ Analysis } & \multicolumn{3}{|c|}{$\begin{array}{c}\text { Discipline offense } \\
\text { percentages }\end{array}$} & \multirow[b]{2}{*}{ Chi-square } & \multirow[b]{2}{*}{ Phi } \\
\hline & AWOL & No AWOL & Total & & \\
\hline $\begin{array}{l}\text { TJTA high-risk group } \\
(13.08 \text { of sample) }\end{array}$ & 3.6 & 95.4 & 100 & $16.41 *$ & .03 \\
\hline $\begin{array}{l}\text { TJTA reduced-risk } \\
\text { group } \\
(87.08 \text { of sample) }\end{array}$ & 2.3 & 97.7 & 100 & & \\
\hline
\end{tabular}

1 Prior to present experiment.

Source: Fort Polk, 1972 post-wide AWOL seminar: Examination of the past, evaluation of the present, and recommendations for the future, Fort Polk, La.: (mimeographed). Undated.

$*_{\mathrm{p}}<.001$. 
There was a small ( $\mathrm{phi}=.03$ ) but statistically significant relationship between TJTA scores and AWOL offenses. Again, compared with results from the ARI control sample, the effect of the Fort Polk program appears to have been counterproductive; more high-risk men went AWOL than had been expected to $(3.68$ versus 3.18$)$.

\section{The Fort Leonard Wood Program}

In 1972 an independent investigation of the relation between AWOL syndrome scoring of the TJTA and AWOL offenses was undertaken at Fort Leonard Wood, Mo. (Rollier, 1972). Table B-5 shows the predictive validity of the TJTA for two BCT brigades: the $3 d$ brigade, which was commanded by COL Rollier, and the $2 \mathrm{~d}$, which was not.

The presence of a small, but statistically significant, relationship between AWOL syndrome scoring and AWOL offenses occurred throughout the $\mathrm{BC} T$ units. However, the relationship was strongest in the $3 \mathrm{rd} \mathrm{BCT}$ brigade (COL Rollier's Brigade), which was the unit with the most active program. Since an effective program should have lessened the degree of relationship (i.e., those identified and helped would have been less likely to go AWOL), this finding again suggests a counterproductive force at work. However, the absence of a control group makes any further interpretation difficult.

The absence of a control group at Fort Leonard Wood also makes it difficult to compare the results at the two posts. The Fort Leonard Wood rates are lower than those for either of the programs at Fort Polk. But it is not clear from the Rollier report whether the figures in Table $B-5$ refer to trainees or to all personnel. This is an important omission, since the rates for permanent soldiers are usually much lower than for trainees and would tend to reduce overall rates. Tables separating trainees and permanent party personnel for the two installations show Fort Wood's rates as higher than Fort Polk's for both types of men (Fort Polk, 1972).

\section{Discussion}

Fraas and Fox's (1972) research casts doubt upon the existence of an AWOL syndrome within prison populations. The weak relationship between AWOL offenses and AWOL syndrome scores in the control group at Fort Polk (Table $1-2$ ) casts similar doubt upon the existence of such a syndrome among troops in BCT. That relationship is strengthened when scores are known suggests criterion contamination. Probably, either some action by the cadre or fellow trainees (scapegoating) or some action by the highrisk soldier (self-fulfilling prophecy) increases the likelihood that men identified as AWOL-prone will, in fact, become AWOL statistics. 
Table $B-5$

TJTA Prediction of AWOL in BCT at Fort Leonard Wood

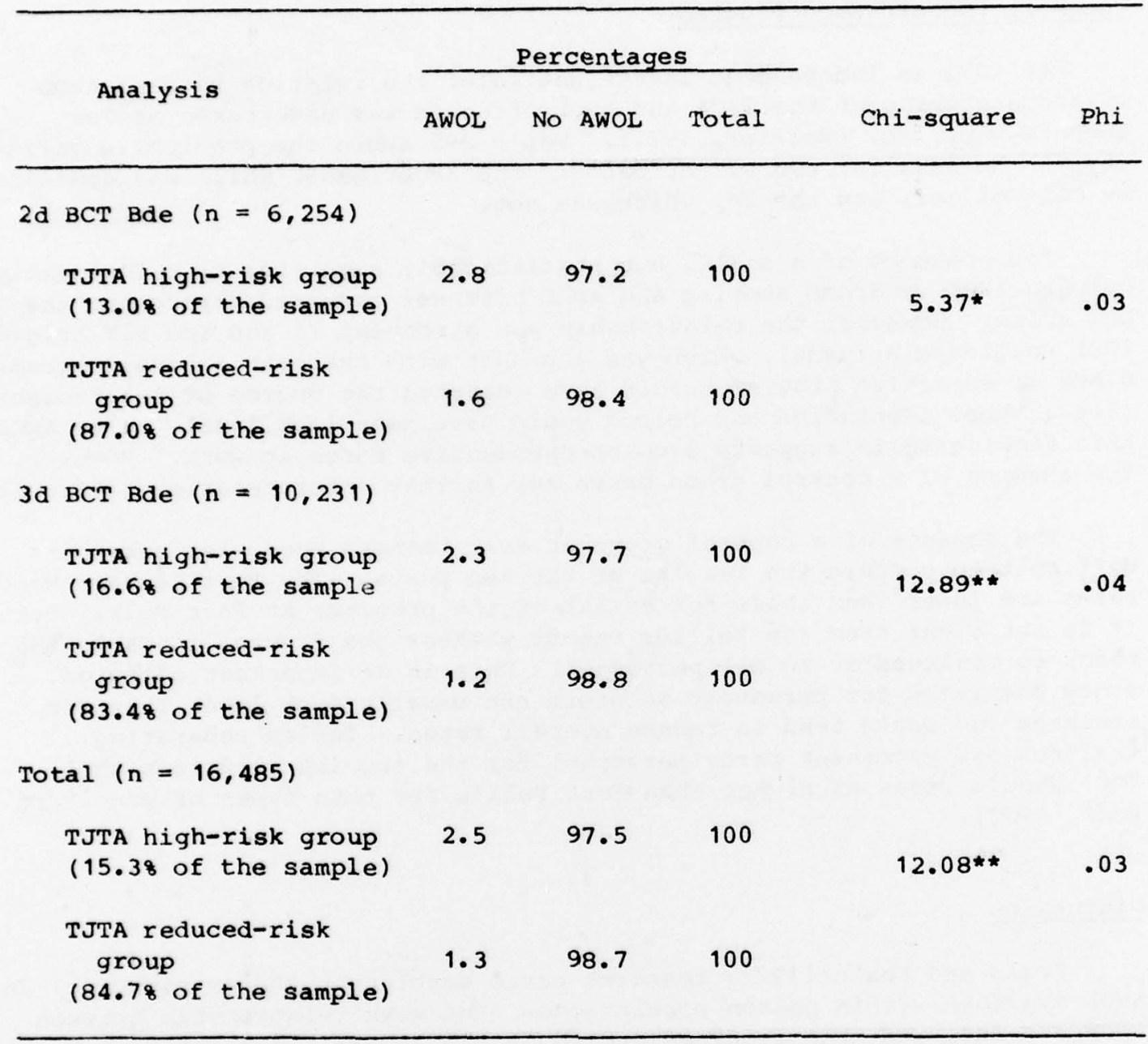

Source: Adapted from Rollier, 1972, Incl 2, Part 2, Annex 01.

*Significant beyond the .05 level.

**Significant beyond the .001 level. 
The lack of information about historical differences between Fort Wood and Fort Polk (e.g.., do the personnel differ? were there any unusual circumstances at either post?) make it difficult to tell what is happening at Fort Wood. Making comparisons between posts is particularly difficult in the absence of a control group at Fort Wood.

However, it does seem clear that the TJTA is not strongly related to AWOL when the scores are not known by the cadre (Fort Polk). Even when the scores are known (Fort Wood and the experimental group at Fort Polk), the magnitude of the relationship is too small to be of any practical utility. 
4 OASD (M\&RA)

2 HODA (DAMI-CSZ)

1 HODA (DAPE.PBR

1 HODA (DAMA.AR)

1 HODA (DAPE-HRE-PO)

1 HODA (SGRD.ID)

1 HODA (DAMI-DOT.C)

1 HODA (DAPC.PMZ-A)

1 HODA (DACH.PPZ.A)

1 HQDA (DAPE.HRE)

1 HODA (DAPE-MPO-C)

I HODA (DAPE-DW)

1 HOOA (OAPE.HRL)

1 HODA (DAPE -CPS)

1 HODA (DAFD.MFA)

1 HODA (DARD.ARS.P)

1 HODA (DAPC PAS-A)

1 HQDA (DUSA.OR)

1 HQDA (DAMO-ROR)

1 HODA (DASG)

1 HQDA (DA 10-P1)

1 Chief, Consult Div (DA.OTSG), Adelphi, MD

1 Mil Asst. Hum Res, ODDR\&E, OAD (E\&LS)

1 HQ USARAL, APO Seattle, ATTN: ARAGP.R

1 HO First Army. ATTN: AFKA-OI-TI

2 HQ Fifth Army. Ft Sam Houston

1 Dir, Army Stf Studies Ofc, ATTN: OAV CSA (DSP)

1 Ofc Chief of Sif, Studies Ofc

1 DCSPER, ATTN: CPS/OCP

1 The Army Lib, Pentagon, ATTN: RSB Chief

i The Army Lib, Pentagon, ATTN: ANRAL

Ofc, Asst Sect of the Army (R\&D)

1 Tech Support Ofc, OJCS

1 USASA, Arlington, ATTN: IARD-T

1 USA Rsch Ofc, Durham, ATTN: Life Sciences Dir

2 USARIEM, Natick, ATTN: SGRD.UE.CA

1 USATTC, Ft Clayton, ATTN: STETC-MO-A

1 USAIMA, Ft Bragg, ATTN: ATSU.CTD-OM

1 USAIMA, Ft Bragg. ATTN: Marquat Lib

1 US WAC Ctr \& Sch, Ft McClellan, ATTN: Lib

1 US WAC Ctr \& Sch, Ft McClellan, ATTN: Tng Dir

1 USA Quartermaster Sch, Ft Lee, ATTN: ATSM-TE

1 Intelligence Material Dev Ofc, EWL., Ft Holabird

1 USA SE Signal Sch, Ft Gordon, ATTN: ATSO-EA

1 USA Chaplain Ctr \& Sch, Ft Hamilton, ATTN: ATSC.TE-RD

1 USATSCH, Ft Eustis, ATTN: Educ Advisor

1 USA War College, Carlisle Barracks, ATTN: Lib

2 WRAIR, Nouropsychiatry Div

1 DLI, SDA, Monterey

1 USA Concept Anal Agcy, Bethesda, ATTN: MOCA.WGC

1 USA Concept Anal Agcy Bethesda, ATTN: MOCA.MR

1 USA Concept Anal Agcy. Bethesde, ATTN: MOCA.JF

1 USA Artic Test Ctr, APO Seattle, ATTN: STEAC-MO ASL

1 USA A,tic Test Ctr. APO Seatzle, ATTN: AMSTE.PL.TS

; USA Aunament Cmd, Redstone Arsenal, ATTN: ATSK.TEM

i USA Atulament Cond, Rock island, ATTN: AMSAR.TDC

1 FAA.NAFEC, Atiantic City. ATTN: Library

1 FAA NAFEC, Allantic City, ATTN: Hum Enur Bt

1 FAA Aeronatical Cit, Okiahoma City, ATTN AAC 4AD

2 USA Flet Arty Sih, Fi Sill, ATTN: Library

1. USA Armor Sct, FI Knox. ATTN: Library

1 USA Armor Sch, fi Knox, ATTN: ATSBDI.E

1. USA A Amor Scl, FI KnOx ATTN AISB-DT TP

i USA Armor Sch, Fi Knox. ATTN: ATSB-CD.AD
2 HQUSACDEC, Ft Ord, ATTN: Library

1 HQUSACDEC, Ft Ord, ATTN: ATEC-EX-E-Hum Factors

2 USAEEC, Ft Benjamin Harrison, ATTN: Library

1 USAPACDC, Ft Benjamin Harrison, ATTN: ATCP-HR

1 USA Comm-Elect Sch, Ft Monmouth, ATTN: ATSN-EA

1 USAEC, Ft Monmouth, ATTN: AMSEL-CT-HDP

1 USAEC, Ft Monmouth, ATTN: AMSEL-PA-P

1 USAEC, Ft Monmouth, ATTN: AMSEL-SI-CB

1 USAEC, Ft Monmouth, ATTN: C, Facl Dev Br

1 USA Materials Sys Anal Agcy, Aberdeen, ATTN: AMXSY - P

1 Edgewood Arsenal, Aberdeen, ATTN: SAREA-BL-H

1 USA Ord Ctr \& Sch, Abercieen, ATTN: ATSL-TEM-C

2 USA Hum Engr Lab, Aberdieen, ATTN: Library/Dir

1 USA Combat Arms Tng Bd, Fi Benning. ATTN: Ad Supervisor

1 USA Infantry Hum Rsch Unit, Ft Benning, ATTN: Chief

1 USA Infantry Bd, Ft Benning, ATTN: STEBC-TE-T

1 USASMA, Ft Bliss, ATIN: ATSS-LRC

1 USA Air Def Sch, Ft Bliss, ATTN: ATSA-CTD -ME

1 USA Air Def Sch, Ft Bliss, ATTN: Tech Lib

1 USA Air Def Bd, Ft Bliss, ATTN: FILES

1 USA Air Def Bd, Ft Bliss, ATTN: STEBD-PO

1 USA Cmd \& General Stf College, Fi Leavenworth, ATTN: Lib

1 USA Cmd \& General Stf College, Fi Leavenworth, ATTN: ATSW-SE-

1 USA Cmd \& General Stf College, Fi Leavenworth, ATTN: Ed Advisor

1 USA Combined Arms Cmbt Dev Act, $F_{t}$ Leavenworth, ATTN: DepCdr

1 USA Combined Arms Cmbt Dev Act, Ft Leavenworth, ATTN: CCS

i USA Combined Arms Cmbt Dev Act, Ft Leavenworth, ATTN: ATCASA

1 USA Combined Arms Cmbt Dev Act, Ft Leavenworth, ATTN: ATCACO-E

1 USA Combined Arms Cmbt Dev Act, Ft Leavenworth, ATTN: ATCACC-C:

1 USAECOM, Night Vision Lab, Ft Belvoir, ATTN: AMSEL-NV-SD

3 USA Computer Sys Cmd, Ft Belvoir, ATTN: Tech Library

1 USAMERDC, Ft Beivoir, ATTN: STSFB-DO

1 USA Eng Sch, Ft Belvoir, ATTN: Library

1 USA Topographic Lab, Ft Belvoir, ATTN: ETL-TD-S

1 USA Topographic Lab, Ft Belvoir, ATTN: STINFO Center

1 USA Topographic Lab, Ft Belvoir, ATTN: ETL-GSL

1 USA Intelligence Ctr \& Sch, Ft Huechuca, ATTN: CTD-MS

1 USA intelligence $\mathrm{Ctr} \&$ Sch, Ft Huachuca, ATTN: ATS-CTD-MS

1 USA Inteiligence $\mathrm{Ctr} \& \mathrm{Sch}, \mathrm{Ft}$ Huachuca, ATTN: ATSI-TE

1 USA Intelligence Ctr \& Sch, Ft Huachuca, ATTN: ATSI-TEX-GS

1 USA Intelligence $\mathrm{Ctr} \& \mathrm{Sch}$, Ft Huachuca, ATTN: ATSI-CTS-OR

1 USA Intelligence Ctr \& Sch, Ft Huachuca, ATTN: ATSI-CTD-DT

1 USA Intelligence Ctr \& Sch, Ft Huachuca, ATTN: ATSI-CTD-CS

1 USA Intelligence $C t r \&$ Sch, Ft Huachuca, ATTN: DAS/SRD

1 USA intelligence $\mathrm{Ctr} \&$ Sch, Ft Huachuca, ATTN: ATSI-TEM

1 USA Intelligence Ctr \& Sch, Ft Huachuca, ATTN: Library

1 CDR, HO Ft Huachuce, ATTN: Tech Ref Div

2 CDR, USA Electronic Prvg Grd, ATTN: STEEP-MT-S •

1 CDR, Project MASSTER, ATTN: Tech Info Center

1 Ha MASSTER, USATRADOC, LNO

1 Research Institute, HO MASSTER, Ft Hood

1 USA Recruiting Cmd, F+ Sherdian, ATTN: USARCPM-P

1 Senior Army Adv., USAFAGOD/TAC, Elgin AF Aux Fld No. 9

1 HQ USARPAC, DCSPER, APO SF 96558, ATTN: GPPE -SE

1 Stimson Lib, Academy of Health Sciences, Ft Sam Houston

1 Marine Corps Inst., ATTN: Dean $-\mathrm{MCl}$

1 HQUSMC, Commandant, ATTN: Code MTMT 51

1 HQUSMC. Commandant, ATTN Code MPI-20

2 USCG Acadiemy. New Lonnon. ATTN: Admission

2 USCG Academy, New London, ATTN: Library

1 USCG Training Ctr, NY, ATTN: CO

1 USCG Trainung Ctr, NY, A TTN : Educ Svc Ofc

1 USCG, Psychol Res Br, DC, ATTN: GP 1/62

1 HQ Mid-Range Br, MC Det, Quantico, ATTN: P\&S Div 
1 US Marine Corps Liaision Ofc, AMC, Alexandria, ATTN: AMCGS-F 1 USATRADOC, Fi Moricce, ATTN: ATRO-ED

6 USATRADOC FI Monroe, ATTN: ATPR-AD

1 USATRADOC, Ft Monroe, ATTN: ATTS-EA

1 USA Forces Cmd, Ft McPherson, ATTN: Library

2 USA Aviation Test 8d, Ft Rucker, ATTN: STEBG-PO

1 USA Agcy for Aviation Safety. Ft Rucker, ATTN: Library

1 USA Agcy for Aviation Safety. Ft Rucker, ATTN: Educ Advisor

I USA Aviation Sch, Ft Rucker, ATTN: PO Drawer O

1 HQUSA Aviation Sys Cmd, St Louis, ATTN: AMSAV-ZDR

2 USA Aviation Sys Test Act., Edwards AFB, ATTN: SAVTE-T

1 USA Air Def Sch, ft Bliss, ATTN: ATSA TEM

1 USA Air Mobility Rsch \& Dev Lab, Moffett Fid, ATTN: SAVDL-AS

I USA Aviation Sch, Res Tng Mgt, Ft Rucker, ATTN: ATST-T-RTM

1 USA Aviation Sch, CO, Ft Rucker, ATTN: ATST-D-A

1 HO DARCOM Alexandria, ATTN: AMXCD-TL

1 HO. DARCOM, Alexandria, ATTN: CDR

I US Military Academy. West Point, ATTN: Serials Unit

1 US Military Academy. Wast Point, ATTN: Ofc of Milt Lorshp

1 US Military Acadenny, West Point, ATTN: MAOR

1 USA Standardization Gp, UK, FPO NY, ATTN: MASE-GC

1 Ofc of Naval Rsch, Arlington, ATTN: Code 462

3 Ofc of Naval Rsch, Arlington, ATTN: Code 458

1 Ofc of Naval Rsch, Arlington, ATTN: Code 450

1 Ofc of Naval Rsch. Arling:on. ATTN: Code 441

1 Naval Aerospc Med Res Lab, Pensacola, ATTN: Acous Sch Div

1 Naval Aerospc Med Res Lab, Pensacola, ATTN: Code L51

1 Naval Aerospc Med Res Lat, Pensacola, ATTN: Code L5

1 Chief of NavPers, ATTN Pers.OR

1 NAVAIRSTA, Norfolk, ATTN: Safety Ctr

1 Nav Oceanographic, DC, ATTN: Code 6251, Charts \& Tech

1 Center of Naval Anal, ATTN: Doc Ctr

1 NavAirSysCom, ATTN: AIR-5313C.

1 Nav BuMed, ATTN: 713

1 NavHelicopterSubSqua 2, FPO SF 96601

1 AFHRL. (FT) William AFB

1 AFHFL (TT) LOWTY AFB

1 AFHRL (AS) WPAFB, OH

2 AFHRL (DOJZ) Brooks AFB

1 AFHRL (DOJN) Lackland AFB

1 HOUSAF (INYSD)

1 HQUSAF (DPXXA)

1 AFVTG (RD) Randolph AFB

3 AMRL (HE) WPAFB, OH

2 AF Inst of Tech, WPAFB, OH, ATTN: ENE/SL

1 ATC (XPTD) Randolph AFB

1 USAF A.roMed Lib, Brooks AFB (SUL -4). ATTN: DOC SEC

1 AFOSR (NL), Arlington

1 AF Log Cmd, McClelian AFB, ATTN: ALC/DPCRB

1 Air Force Academy, CC. ATTN: Dept of Bel Sen

5 NavPers \& Dev Ctr, San Diego

2 Navy Med Neuropsychiatric Rsch Unit, San Diego

1 Nav Electronic Lab, San Diego, ATTN: Ros Lah

1 Nav TrugCen, San Diego A ITN: Corte 9000-Lib

1 NavPostGraSch, Monterey. ATTN: Code 55Aa

1 NavPost GraSch, Monterny, ATTN: Corte 2124

1 Nav TrngEquipCtr, Oriando, A TIN : Tech Lib

1 US Dept of Labor. DC, ATTN: Manpower Admin

1 US Deit of Justice, DC, ATTN: Drug Enforce Admin

1 Nit Bur of Siandards. DC, ATTN: Computer info Section

1 Nat Clearing House for Mit Info, Rockville

1 Denvel Federal Ctr, Lakewood, ATTN: BLM

12 Dofense Documentation Center

4 Dir Psych Army Ha, Russell Ofics, Canberra

1 Scientific Advst, Mil Bd, Army Hq. Russell Ofcs, Canberra

$1 \mathrm{Mil}$ and Air Altache. Austrian Embassy

1 Cintle de Pretherche Dos Factours, Humaine de la Defense

Nationale, Brussels

7 Canidian juint Statf Washinqton

1 Clan Staft, Royal Canaduan AF AITN Pars Std Anal He

3) Chust Cenadian Det Rech Staft. ATTN: C/CROSIW

4 Butisl: Det Staff, British Emtassy. Wastungton
1 Def \& Civil Inst of Enviro Medicine, Canada

1 AIR CRESS, Kensington, ATTN: Info Sys Br

1 Militaerpsykologisk Tjeneste, Copehagen

1 Military Attache, French Embassy, ATTN: Doc Sec

1 Medecin Chef, C.E.R.P.A.-Arsenal, Toulon/Naval France

1 Prin Scientific Off, Appl Hum Engr Rsch Div, Ministry of Defense, New Delhi

1 Pers Rsch Ofc Library, AKA, Israel Defense Forces

1 Ministeris van Defensie, DOOP/KL Afd Sociaal

Psychologische Zaken, The Hague Netherlands 